WSRC-RP-92-1294

\title{
LATE WASH FILTER DEMONSTRATION UNIT PROGRAM
} PLAN (U)

WSRC-RP- -92-1294

by C. A. Nash

DE93 006876

Westinghouse Savannah River Company

Savannah River Site

Aiken, South Carolina 29808

Other Authors:

This paper was prepared in connection with work done under Contract No. DE-AC09-89SR18035 with the U. S. Department of Energy. By acceptance of this paper, the publisher and/or recipient acknowledges the U. S. Government's right to retain a nonexclusive, royalty-free license in and to any copyright covering this paper, along with the right to reproduce and to authorize others to reproduce all or part of the copyrighted paper. 


\section{DISCLAIMER}

This report was prepared as an account of work sponsored by an agency of the United States Government. Neither the United States Government nor any agency thereof, nor any of their employees, makes any warranty, express or implied, or assumes any legal liability or responsibility for the accuracy, completeness, or usefulness of any information, apparatus, product, or process disclosed, or represents that its use would not infringe privately owned rights. Reference herein to any specific commercial product, process, or service by trade name, trademark, manufacturer, or otherwise does not necessarily constitute or imply its endorsement, recommendation, or favoring by the United States Government or any agency thereof. The views and opinions of authors expressed herein do not necessarily state or reflect those of the United States Government or any agency thereof.

This report has been reproduced directly from the best available copy.

Available to DOE and DOE contractors from the Office of Scientific and Technical Information, P. O. Box 62, Oak Ridge, TN 37831; prices available from (615) $576-8401$.

Available to the public from the National Technical Information Service, $U$. $S$. Department of Commerce, 5285 Port Royal Rd., Springfield, VA 22161.

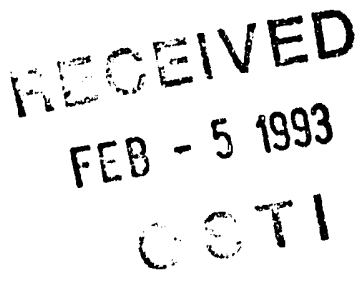


November 13, 1992

OPS-DTF-920064

TO: $\quad$ E. W. HOLTZSCHEITER

$$
\begin{aligned}
& \text { MANAGER, } \\
& \text { DEFENSE WASTE PROCESSING TECHNOLOGY } \\
& \text { SAVANNAH RIVER TECHNOLOGY CENTER }
\end{aligned}
$$

FROM: J. A. GENTILUCCI
TECFINICAL ISSUES TO BE ADDRESSED BY A LATE WASH FILTER
DEMONSTRATION UNIT (U)

Ref. 1. WSRC-RP-92-793 (Rev. 2), DWPF Late Washing Technical Bases, 9/8/92.

2. WSRC-TR-92-360-2, DWPF Late Wash Facility Functional Performance Requirements, 9/11/92.

3. WSRC-RP-92-800, Functional Performance Requirements for Late Wash Filter Demonstration Unit, 8/5/92.

Technical feasibility of the Late Wash process has been established by SRTC development work (Ref. 1), establishment of performance requirements (Ref. 2), and completion of conceptual design, including Formal Design Review. It was recognized early in the development period that an engineered pilot scale facility would be desirable to demonstrate Late Washoperating and cleaning parameters with full length filter elements and comparable quantities of irradiated simulated precipitate waste.

It is not considered essential to demonstrate and optimize various aspects of In-Tank Precipitation as well as Late Wash performance in a pilot scale facility. These aspects include:

- defining optimum conditions during normal washing operations

- defining optimum conditions for filter cleaning and lay-up 
E. W. Holtzscheiter

OPS-DTF-920064

Page 2

November 13, 1992

- $\quad$ testing prototypical control and monitoring features

- testing potential process and equipment improvements

A filter demonstration unit will provide comparable benefits to the existing PHEF, IDMS, and Canister welding semiworks.

The Functional Performance Requirements (FPR) for such a unit are described in Ref. 3. A conceptual design package with estimate of cost and schedule is being prepared by BSRI.

SRTC is requested to provide a program plan for design and operation of a Late Wash Filter Demonstration Unit. Following is a summary of the technical issues to be addressed by this plan.

\section{Outline of Technical Issues}

Concern: Optimum performance of full length and full diameter filter elements. Criteria: Specify operating parameters to obtain maximum washing effectiveness (removal of nitrites) within the constraints imposed by DWPF feed requirements and cycle times. Investigate effects of irradiation equivalent to aging the precipitate up to a minimum of 2 years. Include effects of mercury and noble metals.

Concern: Removal of benzene from the filtrate.

Criteria: Specify sparging parameters to reduce the benzene content of the filtrate to safe levels for return to the Tank Farm.

Concern: Optimum usage of chemicals and backpulsing for cleaning filter elements.

Criteria: Specify optimum techniques for removing precipitate that remains on filter surface and in filter pores while minimizing handling requirements for radioactive cleaning solutions.

Concern: Optimum techniques and instrumentation for process control.

Criteria: Test Prototypical control systems and monitors to establish safe and effective process operations.

Concern: Capability to test improved filter designs and washing cycles.

Criteria: Provide flexibility to install and test a range of filter types and orientations, backpulsing arrangements, and cleaning cycles. 
E. W. Holtzscheiter

OPS-DTF-920064

Page 2

November 13, 1992

Concern: Prevention of foaming during filter operation and cleaning.

Criteria: $\quad$ Provide capability to add antifoaming agents and to monitor for effectiveness. Ensure compatibility with both Late Wash, DWPF, and Interim Waste Operations.

Concern: Filtrate or cleaning materials may not be compatible with Interim Waste and Saltstone.

Criteria: $\quad$ Filtrate meets criteria for Saltstone operations. Criteria: The filtrate and cleaning materials meet chemical compatibility and corrosivity requirements of Interim Waste.

Any questions concerning this request may be directed to W. J. Vetsch (7-1043).

WJV:mfh

cc: D. B. Amerine, 704-S

J. F. Ortaldo, 704-S

L. Papouchado, 773-A

C. A. Nash, 704-T

D. H. McGuire, 704-27S

J. T. Carter, 704-T

M. D. Boersma, 704-T

L. F. Landon, 704-T

R. A. Jacobs, 704-T

W. J. Vetsch, 704-S

Document Control, 704-71S 
LATE WASH FILTER DEMONSTRATION PROGRAM PLAN (U)

NOVEMBER 10, 1992

Prepared By:

C. A. Nash

S. A. Budenstein

M. D. Boersma

Approved By: $\frac{\sum \text { thetzahel }}{\text { E.W. Holtzscheiter, Manager }}$

Defense Waste Processing Technology

\section{SAVANNAH RIVER TECHNOLOGY CENTER}

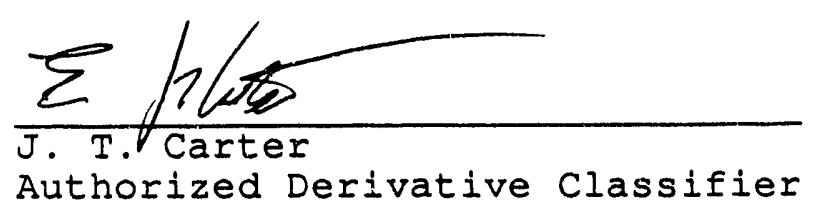


PROGRAM PLAN - LATE WASH FILTER DEMONSTRATION

A non-radioactive engineexing demonstration of the DWPF Late Wash Facility (LWF) for washing salt precipitate feed, and of the In-Tank Precipitate (ITP) filters, is planned. The scale will be 0.05 to 0.1 , with some larger components, prototypical instruments, and full-length filter elements. Precipitate slurry for late wash tests will be fully irradiated (3E08 rads). Program needs and objectives are to demonstrate LWF design, optimize LWF process operations including filter cleaning and benzene sparging, test actual instruments including benzene and nitrite monitors, and test advanced design concepts such as etched filters. In addition, the Late Wash Filter Demonstration Unit (IWFDU) will support the operation and long-term improvement of ITP filtration. The expected cost of the LWFDU is $\$ 1.8$ million. Operating costs in FY 1993 are expected to be $\$ 1.0$ million. Testing is expected to begin 3QFY93, with LWF design confirmation and LWF operations bases completed by the end of 1QFY94.

\section{PROGRAM BACKGROUND}

Potassium/cesium tetraphenylborate (K/CsTPB) precipitate slurry from ITP will be stored for $1-3$ years in Tank 49 . During storage, the aqueous phase must be inhibited with NaNO2 and $\mathrm{NaOH}$ to minimize tank corrosion. Also during storage, sume of the $\mathrm{K} / \mathrm{CsTPB}$ radiolytically decomposes, generating other organic compounds (both soluble and insoluble) and redissolving part of the cesium.

The (NO2-) corrosion inhibitor and certain soluble organic radiolysis products interfere with processing the precipitate in DWPF by catalyzed acid hydrolysis. Also, the amount of sodium in the corrosion-inhibited liquid may challenge the DWPF glass acceptance limits, depending upon the actual inhibitor ratio (NaOH:NaNO2) and on the amount of sodium allowed in the washed sludge feed stream. Therefore, just before the precipitate slurry is pumped into the DWPF for acid hydrolysis, each batch will be washed with water to remove (NO2-), soluble organics, and sodium. This is called "Late" Washing ( $L W$ ), to distinguish it from the initial washing of the precipitate in ITP.

LW will be accomplished in a stirred tank and external filter system, with fresh water being added to the tank at the same rate that filtrate (containing solutes) is removed. The filter will consist of a bundle of about 150 porous metal tubes operated in the inertial crossflow mode. Similar filters are used in ITP to concentrate and initially wash the precifitate. In addition to slurry washing, the LWF processes will include: 
1. An initial batch reprecipitation of any dissolved Cs (and $K$ ) by adding NaTPB.

2. Reconcentrating (dewatering) the slurry to about 10 wt: solids by filtration, if necessary, to remove transfer line flush water and/or to increase washing efficiency.

3. Stripping soluble radiogenic benzene from the filtrate using nitrogen sparging in the filtrate collection tank. The filtrate will be returned to a tank that is not equipped to handle flammable vapors.

4. Periodic in-situ cleaning of the filter tubes by water and chemical flushes.

5. (Possible, but not in current scope) Extended ir-situ cleaning of worn or darnaged filters for disposal as low-level (nonhazardous) waste.

Design of the LWE will be based on ITP design and experience; and on bench-scale testing (ref. 1) of single short filter elements $(0.0006$ scale) using precipitate slurry that had been irradiated to $3 E 08$ rads, the equivalent of 2 years' storage in Tank "9 -i.e., LW conditions. This bench-scale work also provided vasic design data on in-situ filter cleaning for $L W$. Technical design bases for benzene stripping and other LWF operations are summarized in ref. 2 .

Key differences between ITP design and LW conceptual design (ref. 3) include:

1. Slurry tank size, ca. 1,000,000 gallons in ITP vs. 10,000 gallons in LWF.

2. Vertical filter orientation in LWF vs. horizontal in ITP. In conjunction with this the filter shells have different end geometries.

3. Multiple backpulse ports in the IWF filter shell vs. single port in ITP.

4. Helix slurry recirculation pump in $L W$ vs. vortex in ITP.

\section{PROGRAM NEEDS}

Although there are no technical feasibility issues or basic design data needs for the LWF, the entire LWF design should be demonstrated on an engineering scale before hot startup, scheduled for 10/95. This is standard and sound practice for any new nuclear processing facility, and it is also in keeping with all other parts of DWPE: the 0.2 scale PHEF; the 0.11 scale IDMS; full scale frit blasting and canister welding semiworks; as well as numerous pump, instrument, sampler, and other component tests. 
Equally importantly, a semiworks LW test unit is needed to provide basic operational data for IWF procedures and process optimization. Filter cleaning, in particular, will be demonstrated and optimized in full-length filter units, to minimize cycle time, chemical usage, and secondary waste. filtrate sparging with nitrogen to remove benzene will be optimized in a large tank with irradiated filtrate. Such information is needed to shorten LWF cold runs in order to meet the 10/95 startup schedule and support both DWPF and waste Removal.

In addition, a test bed is needed to test advanced equipment designs, such as alternative filters that could improve ITP, LW, or both.

Finally, a tank/pump/filter test loop is needed to support both ITP and LWF in terms of future flowsheet changes, unforeseen conditions, equipment vendor changes, and process optimization.

PROGRAM FACILITY DESCRIPTION

The LWFDU is a $0.05-0.1$ scale volumetric throughput, nonradioactive, working model of the DWPF LWF. The LWFDU includes a 500-gallon, agitated, slurry reprecipitation and wash tank; a 1200-gallon filtrate collestion tank with sparger for benzene stripping; and several smaller chemical tanks. All tanks will be obtained from other programs at no cost except for cleaning and relocation. The filter loop includes a filter test stand in which full-length (10 ft.; multitube filters can be installed horizontally or: vertically. Likewise, the slurry recirculation pump stand can accept various pump designs including the initial helix (IW) and a vortex (ITP) type. A partial filter bypass will be provided in crder to test pumps that are not available in $<0.1$ scale. The filtrate line will contain a gas-driven backpulse pot of $L W$ design, and the slurry recirculation line will contain a LWdesign variable flow resistor to control transmembrane pressure.

The entire LWFDU will be instrumented to simulate LTF control instrumentation, and to acquire additional technical data. Some instruments such as the at-line benzene and nitrite analyzers will be prototypical or even actual LWF equipment (for preinstallation checkout).

The LWEDU will be located at the north end of Building 675-T, TNX. This is the original DWPF scale Melter location, and all needed services are available except high-pressure gas for filter backpulsing, deionized water, and $\mathrm{N}_{2}$. Dikes and ventilation will be provided to control spills and any resultant toxic vapors such as benzene and mercury. Tanks will be vented directly to the atmosphere outside of the building. 


\section{PROGRAM OBJECTIVES}

The program objectives are initially focused on LWF, although some pertain to ITP as well. However, the first tests in the LWFDU will use unirradiated precipitate slurry, both to obtain baseline data and also because of cost and availability. These tests will produce ITP-relevant results that are not reflected in the listed objectives.

Objectives are given below in a general priority order. This order could change, and objectives could be added or deleted as LWF final design progresses and as the $L W$ and ITP programs mature. For example, should ITP encounter an unforeseen process problem, or should LWF need early results on some specific aspect of the process, priorities would be shifted.

1.* Validate the LWF processes and design concepts with a full length multitube filter at 0.05 throughput scale and nominal process conditions.

2.* Provide detailed bases for LW filter cleaning procedures and chemical usage.

3.* Determine operating parameters for benzene stripping in a deep tank with filtrate from actual irradiated feed.

4.* Demonstrate and characterize high-impulse backpulsing with multiple, axially distributed backpise ports; optimize backpulse parameters Eor LW.

5.* Test prototypical and/or actual LWF special instruments including benzene and nitrite monitors.

*The above 5 objectives are considered essential to ensure $10 / 95$ startup of LWF.

6. Thoroughly characterize full length multitube filter performance ( $f$ ux and DF as a function of transmembrane pressure TMP), axial velocity, slurry properties including oo solids and shear history, time, slurry rank agitation, surfactant, and other parameters. Initially, thi- will be done using iriadiated feed and vertical filter; later in priority, using unirri liated feed with horizontal filter, although some unirradiated feed data will be obtained incidental to facility run-in.

7. Determine filter fouling patterns for irradicted feed and vertical filter.

8. Test 0.1 scale (14-tube) filter to address any scale factors involved with filter performance or cleaning. 
9. Characterize horizontal and vertical filter orientations with regard to draining/flushing, fouling rate, and cleanability.

10. Test alternative filter (etched disc) with both irradiated and unirradiated slurry.

11. Test both vortex and helix pumps with irradiated and unirradiated slurry.

12. Test ultrasonic filter cleaning, both alone and as an adjunct to chemical cleaning.

13. Develop filter cleaning for disposal.

PRCGRAM TIMING

The schedule for hot startup of LWF is October, 1995. It is important to meet this goal because ITP is scheduled to start up in FY93, and Tank 49 could fill up with precipitate in 2-3 years of ITP operation. In addition, it is important to begin salt precipitate feed to DWPF as soon as possible because every day of "sludge only" operation translates into more glass canisters, at a very high unit cost.

The LWF schedule allows very little time for run-in and cold operations ( 4 months). The LWFDU can expedite LWF hot startup by providing technical bases for operating procedures, and design confirmation, before LWF cold ops. Thus, the LWFDU should be built and operates as expeditiously as possible.

\section{L'NEDU "BEST CASE" SCHEDULE}

\section{Program Step}

Establish functional performance requirements

Secure Tanks, Bujlding Space

Design Proposals (2)

Design

Procure Key Equipment (filters, pumps) requisition

order

vendor fab \& delivery (23 weeks)

Construction

Procure Chemicals

irradiate 200 gal. feed \& Ga. Tech

Prepare Task Plans, Procedures

Training

Run-in

Start Chemical Testing

Complete Program Objectives 1-5

Complete All Initial Program Objectives
Start Complete

$08 / 05 / 92$

$09 / 15 / 92$

$10 / 09 / 92$

$11 / 15 / 92 \quad 02 / 15 / 93$

$09 / 29 / 92$

$10 / 15 / 92$

$03 / 15 / 93$

$05 / 93$

$10 / 01 / 92 \quad 03 / 93$

$11 / 92 \quad 04 / 93$

$03 / 93 \quad 04 / 93$

$04 / 93 \quad 05 / 93$

$05 / 93$

$12 / 93$

$05 / 95$ 
PROGRAM CCSTS

Only preliminary cost estimates are available. The LWFDU design and construction costs wert estimated by BSRI. The project will be cost-funded. Filter and slurry pump costs are not firm vendor quotes but are reasonably accurate. Irradiation costs are based on preliminary discussions with Georgia Tech personnel. Other costs (chemicals, manpower) are DWPT estimates.

\section{Item}

Estimating

Design

Special Pumps \& Filters

Prototypic Instruments

Construction (BSRI)

Project Mgt.

Contingency $25 \%$

Total Project

operate

Exempt SRTC Staff

Tech/Operators

TNX Maint.

Analytical

Chemicals

Irradiation

Equip/Mods/EWRs

Contingency $15 \%$

Total Operations

Total Program

$\begin{array}{r}\text { EY93 } \\ 30 \\ 372 \\ 110 \\ 95 \\ 800 \\ 45 \\ 363 \\ \hline\end{array}$

1815

1815

cosT, \$K

372

95

800

363 (through $5 / 95$ )

Total Program

1815

300

880

290

1020

70

265

$50 \quad 270$

$50 \quad 110$

$70 \quad 170$

$40 \quad 100$

$130 \quad 420$

$1000 \quad 3235$

$2815 \quad 5050$

PROGRAM EXECUTION AND CONTROL

The Defense Waste Processing Technology (DWPT) Section of the Savannah River Technology Center (SRTC) Division will be responsible for most aspects of this program including planning, management, functional design requirements, procurement, procedures, QA, safety, operations, data reduction and interpretation, and reporting.

Bechtel Savannah River, Incorporated (BSRI) will design the LWFDU, using key members of the DWPF Late Wash design team including Bechtel National, Incorporated (BNI) personnel. This will maximize congruency with, and relevancy to, the DWPF LWF. 
The I.WFDU will be constructed by BSRI or another contractor TBD.

The LWFDU experimental $t$ m will consist of a Lead Engineer; up to two other Engineers from time to time depending upon needs for shift coverage, data reduction, etc.; a Senior Advisory Engineer; two fully assigned Technicians; four other Technicians, or Operators, on a temporary basis for round-the-clock testing; their Supervisors; and DWPT Management. This Team will be supported by the TNX Operations and Maintenance staff; DWPT and/or other SRTC Analytical groups; and Industrial Hygiene and other general support groups as needed. Close liason will be maintained with DWPF and WM/ITP Technical and Engineering, and SRTC/Interim Waste Technology Section pe:sonnel.

All tests will be conducted using approved written procedures.

A WSR.C Peer Review Group will be formed to review the LWFDU Program. This Group will include technical personnel from DWPF and ITP, as well as from other SRTC sections. At least two peer reviews will be conducted, the first one near the beginning of ac'cual cesting. Other reviews and surveillances by the Department of Energy or its Contrnctors will be conducted upon request. All formal review recommendations and concerns will be addressed.

Individual technology issues concerning Late washing will be managed and tracked under the DWPF Technology Assurance Program (SRI-PMC-92-0008). A Technology Issue Coordinator and Team will be named for each issue. Issue resolution schedules and other key LWFDU milestones will be included in the DWPF Integrated Schedule (Prima Vera program). In addition, the LWFDU program will be periodically reviewed and steered at thC DWPF System Integration Plan of the Week (POW) meeting, which includes and informs DOE representatives as well as upper management of both the waste Management and Environmental Restoration and the SRTC Divisions of WSRC.

The IWFDU Program will be conducted under quality assurance procedures contained in DWP\&HT QA Procedures Manual 1Q43. Sitewide and local Total Quality, Safety, Health, Energy Conservation, Emergency Preparedness, Cost Reduction, General Employee Training, and other such programs will be brought to bear on the LWFDU Program. Compliance with environmental regulations and permits, OSHA regulations, and other applicable regulations and orders will be strictly maintained. 

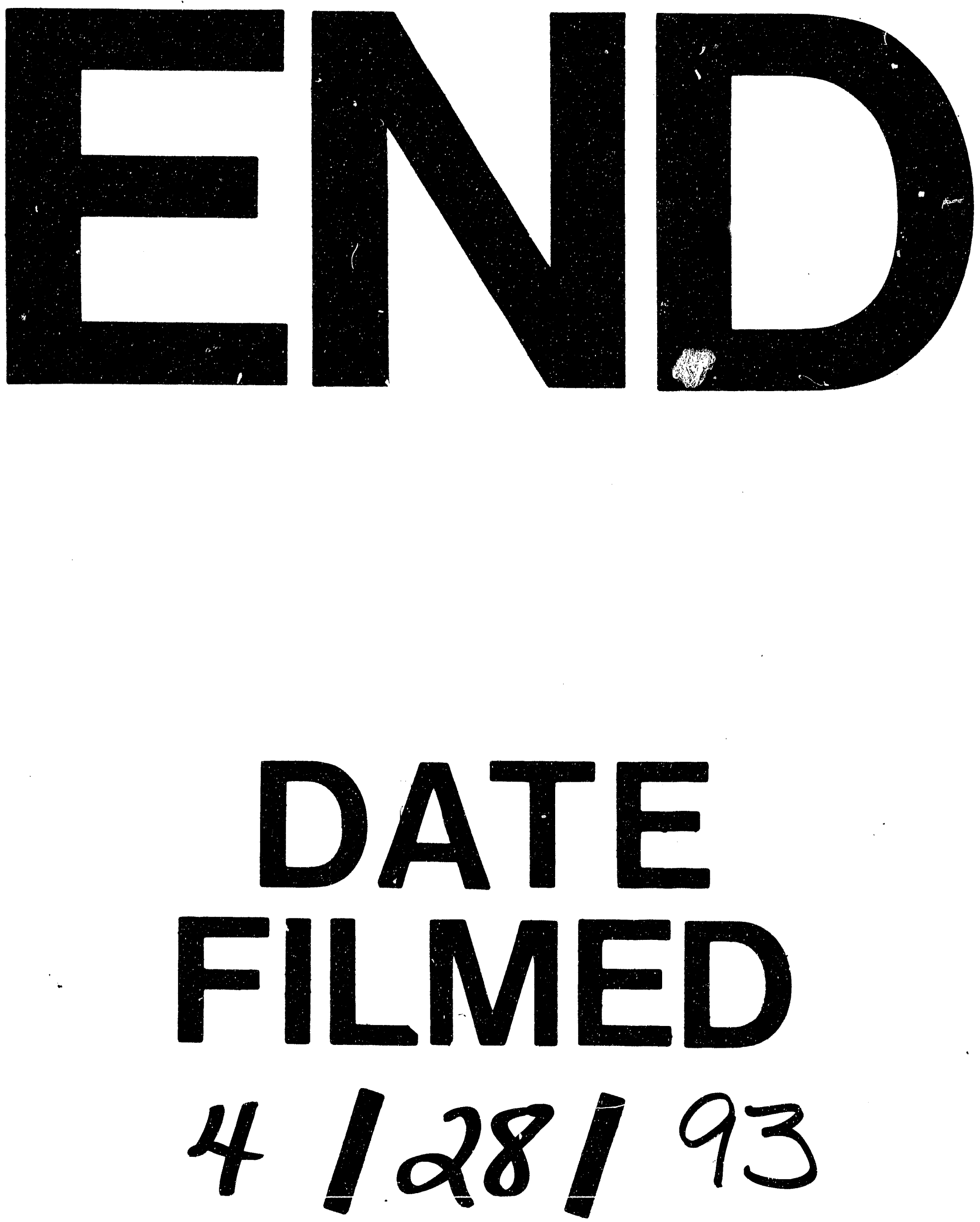
